\title{
Research on symbolic consumption in fashion culture spread Yugang Chen ${ }^{1, a}$ \\ ${ }^{1}$ Jiangxi Institute of Fashion Technology, Jiangxi, Nanchang, 330201 \\ a28941204@qq,com
}

Keywords: Architectural modeling; Clothing design; Solid; using

\begin{abstract}
In this paper, the concept of semiotics and communication of fashion culture in symbolic consumption characteristics were analyzed, focused on the clothing culture of communication channels and symbolic relationship between fashion and cultural and symbolic relationships, and dress culture symbolic consumption, noted cultural symbols of apparel study has important theoretical value and significance to guide social consumption, values and ideas.
\end{abstract}

\section{Introduction}

Dress culture is the crystallization of uniquely human material civilization, it also has the connotation of spiritual civilization. World after a long time the human society from ignorance to civilization, from wore animal skins and leaves cover to keep warm, to create the beautification function and utility function of costume culture, people will become the aesthetic taste, color preference, attitude toward religion, to the extent of the cultural concept to accept, all precipitation in the costume culture, formed the spirit connotation of costume culture. When costume culture to a certain point of interest for the social widespread acceptance, has been widely promotion, then the process of gradually disappear, we call it fashion, is also popular. Will interest points are derived by using the art means, abstract language to express people's emotion, and in the crowd, widely spread in the society, the meaning symbol information through a wide range of transmission, become widely popular or accept the image of the language, we call the image language symbol. Symbolic expression of language can't express the abstract concept, on the one hand to thinking outside of the image and the concept of clear people's identification; On the other hand also reflected the people will pick the outside world for the spread of autonomy; And media as a platform for propaganda, introduces the dissemination of information is the main content of the work, the communication platform between communicators and recipients of information transmission, the spread of fashion culture through the media, constitute the symbolic communications and consumer trends. The symbolic consumption is how? Next in this paper, the transmission channel and symbolization, the relationship between fashion culture and the symbolic relation, and the symbolic consumption of dress culture, discusses the analysis.

\section{Media and symbolization}

Media is the carrier of communication content, communication media is a means of passing information, by telephone, network, television and other media about the communication technologies; Media is information collection, processing, production and transport organization, such as newspaper, radio, television, etc. The propagation speed, the scope of social information and efficiency depends on the advanced technical means of the media or not, but the spread of the content and orientation depends on the organization's media statute, ideology, etc. Symbol is the alleged symbol or sign on behalf of the other things, it is the carrier of information, made up of the connotation of the spread of [2]. Symbols and media is different: media media is the carrier of symbol, does not refer to other things, also does not directly represent the content of the transmission. Symbol reflects the process of the cognition of things, also has the logic of dissemination of information, so the more abstract symbols, orderliness, it is people thinking the expression form of language. And media as a physical entity, reflects the physical form, size 
morphology characteristics, such as portable, can be damaged, between the media and symbol, belong to the relationship between the hair and skin; Symbolic language is the people's thinking, refine, and widely accepted by the audience, media and symbolic interaction, symbolic have a guiding role on the popular trend, and the media of symbolization, achieved the goal that drives the fashion trend, which makes the public to accept the symbol to deliver content, also let the symbol of the virtual value obtained the widespread dissemination.

\section{And the impact of symbolic consumption}

The post-industrial forming, it is made in social consumption and consumption behavior. The transformation of society has given rise to the transformation of the way people live, the transition from production society to consumer society. Content was great expansion of consumption, it has the daily life of materialized, also has the material information, also has an abstract social identity, awareness, taste and personality, such as symbol, today's symbolic language is a kind of new image, which is in the modern age, people use the new totem, symbolic consumption has become a trend in today's society.

The symbolic consumption to promote the prosperity of the economy, consumer also quietly to the qualitative change, the nature of people from a single physical needs, to the needs of both physical and chemical requirements and independent desire, promoted the openness of the society. Symbolization of items, namely to hierarchy, people free will pick of matching items, and their own economic strength to compare in the symbols of differences, and differences in levels of symbol products and stimulate consumption, physical needs and requirements of inner desire for each other, to expand the space of consumption. Consumption symbol lead the fashion trend of consumption, consumption has become a symbol of luxury, alternative, grade of consumption, also make the consumption purposes in diverse qualities, highlighted by differentiation of the virtual value of the products, combined with the mode of transmission of accelerant, attract consumer's attention and attention, and touch the consumers deeper spiritual consumption, make the products and consumers, emotion, desire, etc, to achieve the purpose of consumption around.

\section{The symbolization of fashion culture}

Dress symbolization. Clothing after art, creative thinking, giving it the meaning of the symbol, and fixed, enriching its image language, won a widely accepted and approved, we called the symbolization of clothing. For the wearer, is individual grade and be fond of the autonomy of choice, is economic strength corresponding choice; In public, clothing represents the value orientation of individual or group, is a silent individuals or groups, give a person visual sense at the same time, also to guide the public recognition. Designed with the aid of clothing to show platform, passing clothing language of innovative thinking, meet the market demand for clothing, and the style, taste and aesthetic level ladder, guide the symbolization of consumers desire demand.

The spread of popular clothing culture. The tradition clothing is the characterization of specific identity, status, and the information age today, luxury, such as brand symbols represent the power of the clothing, the commercial sense to replace the honour low order and meaning, the dress today's clothing culture, civil, commercial, trend into the mainstream. As informatization promotion, a large number of media and the interests of the business culture transmission, make clothing has become the point of interest and constantly fashionable hot spots, the connotation of clothing culture was injected with high-tech, high-tech into the modelling of dress development; Clothing production and sales, are endowed with high-tech content.

Information makes the transmission channel from print to television, from radio to the network, the spread of the transmission of various channels of costume culture, under the information age, clothing, tend to be diversified. People autonomy to reveal personality psychology, dress out of convergence and towards the personalized; And informatization promotes the dress popular indefiniteness, people life rhythm speeding up, the informationization also speed up the pace of social change, fashion center, fashion hot emerge in endlessly, also lost the fashion center, and fashion focus of hot spots, the dress culture becomes full of sensibility and vigor of popular culture, 
costume culture has become diversified, the mode of existence of contradictions.

Dress culture of symbolic consumption. At present, the consumption culture and visual culture has deep social levels. In the traditional sense of the consumer, is the main functional and aesthetic choices, and the relationship between the clothing relatively direct, just clothing apparel consumption expression of use value and aesthetic preferences. In consumer culture, people not only in a relationship and dress, can also be symbolic consumption relationship, the consumption function and aesthetic incomplete expression of dress, symbolic meaning beyond the physical meaning of dress, the pursuit of fashion taste, virtual value pursuit, make clothing symbols have the virtual value of traditional value. Virtual value to construct the perceptual consumption, make material consumption both on the level of spirit, desire to express, joined the clothing culture, and the media to stimulate the people sense that transmission channel of the diversification of demand, dress symbolization of triggered the change of ideology, internal symbolic greatly restricted the value orientation of the consumption of clothing, the clothing consumption, and consumption of symbol.

Symbol consumption has become a common social phenomenon, the important content of symbolic consumption culture and media is constructed and costume culture symbolic consumption, not only marketing clothing, also guide the public consumption choices for clothing, dress culture symbolic also created the virtual value of dress, the consumption level of ladder is the elaboration of apparel categories, is also the consumption level of alienation, further influence on people's ideology. As people's attention on to the symbolic significance of consumption, people had an differentiation, inner desire makes consumption stimulates the clothing culture and media integration and symbolization, the traditional costume culture is not only a functional and aesthetic orientation, has increased the guide of perceptual consumption, expand the dress contains the meaning of consumption. The differences of clothing, personalized promoted will dress to classify, make each dress on behalf of its implications, which restrains people's consumption behavior, distinguish between the taste of people from the clothing consumption, economic strength, status, and personality traits.

\section{Conclusion}

Interpreted from the positive significance, dress culture of symbolic consumption, is the pursuit of the manifestation of personality differences. Dress culture symbolic significance, explained the evolution of the current people ideological concept, is a rational concept of perceptual expression, personalized characteristics, the characteristics of novelty, became a symbolic emphasis on clothing, also an individual's desire to dress; Demand individuation, having a unique style in the abstract constructs the logic of consumption, make clothing culture to provide personalized consumption may, same personalized orientation also influence the development of costume culture, and the media to guide is also a great social value and ideas, through the media spread the popularizing symbolization of costume culture, lead the people to the clothing personalized demand, stimulate the potential of the social innovation and creation, also promoted the development of the economy.

\section{Reference}

[1] enami. New modernism costume context based on semiotics analysis [J] journal of wuhan university of textile, 2015 (04) : 11-14.

[2] Shao Xiaohua. Try to talk about the symbolization of Chinese costume culture [J] the BBS of Chinese culture, 2015 (7) : 23-27..

[3] xiao-wei sun; Wang lixin. Theory of costume culture dissemination and costume sales of the new network model [J] China leather, 2011 (12) : 34 to 37.

[4] Ceng Qi. Fashion culture spread in the symbolization characteristics research [D] the sichuan university, 2006 (05). 